\title{
Produção de novos significados na sociedade do cansaço: o ensino de design da informação à luz dos questionamentos de Byung-Chul Han
}

\author{
Production of new meanings in the society of tiredness: information design \\ teaching in light of Byung-Chul Han's questions
}

Ana Dias de Alencar e Ricardo Artur Pereira Carvalho

ensino de design, pensamento visual, sociedade do cansaço, contemporaneidade

Este artigo pretende instigar reflexões acerca do ensino de design da informação na atualidade, tendo como principal referencial teórico os questionamentos expostos pelo filósofo sul-coreano Byung-Chul Han. Abordando o esgotamento da sociedade do século XXI, bem como a temporalidade do processo de criação digital ao qual os alunos e alunas estão submetidos, este trabalho tece conexões entre as ideias de Han e de teóricos do campo do design - ou próximos a ele - , a fim de se pensar o estímulo ao equilíbrio entre as habilidades técnicas e o pensamento visual destes estudantes. Nesse sentido, aponta também para a necessidade de se reconsiderar os processos pedagógicos e avaliativos, enraizados nas noções de desempenho, urgência, controle e rigidez, com o intuito de conduzir a outras relações de ensino-aprendizagem e possibilitar - através da priorização da subjetividade, da observação minuciosa da informação e da criação lenta - a produção de novas mensagens e significados.

design education, visual thinking, society of tiredness, contemporaneity

This article intends to instigate reflections about the teaching of information design today, having as main theoretical reference the questions raised by the South Korean philosopher Byung-Chul Han. Addressing the exhaustion of 21st century society, as well as the temporality of the digital creation process to which students are subjected, this work weaves connections between the ideas of Han and theorists in the field of design - or close to him —, in order to think about stimulating the balance between the technical skills and the visual thinking of these students in pedagogical practices. In this sense, it also points to the need to reconsider the pedagogical and evaluative processes, rooted in the notions of performance, urgency, control and rigidity, in order to lead to other teaching-learning relationships and to enable - through the prioritization of subjectivity, of minute observation of information and slow creation - the production of new messages and meanings.

\section{Introdução}

A preocupação com o equilíbrio entre as habilidades técnicas e o desenvolvimento do pensamento visual na formação de novos designers pode ser observada desde a formação das primeiras escolas de design. Se o design moderno do início do século XX trabalhava a técnica e o raciocínio projetual através do ensino de conceitos visuais universais - contestados, mais

Anais do $10^{\circ} \mathrm{CIDI}$ e $10^{\circ} \mathrm{CONGIC}$

Kelli C.A.S. Smythe, Rafael de Castro Andrade (orgs.)

Sociedade Brasileira de Design da Informação - SBDI

Curitiba | Brasil | 2021
Proceedings of the $10^{\text {th }} \mathrm{CIDI}$ and $10^{\text {th }}$ CONGIC

Kelli C.A.S. Smythe, Rafael de Castro Andrade (orgs.)

Sociedade Brasileira de Design da Informação - SBDI Curitiba | Brazil | 2021 
à frente, pelo pós-modernismo -, hoje, teóricos e educadores do campo pensam questões que tangem a comunicação frente ao avanço das novas tecnologias da era digital.

De acordo com Jacobson (2000), para além da expressão artística, o pensamento visual, uma vez organizado e estruturado, age potencialmente no sentido de solucionar problemas. Quando os produtos visuais do design da informação não possuem a capacidade de informar, ensinar, explicar a uma determinada audiência (Lipton, 2007; Wildbur \& Burke, 1998), podem denunciar uma falha na conceituação do pensamento ou na organização de ideias e dados.

Ainda segundo Jacobson (2000), cada indivíduo é, simultaneamente, produtor e consumidor de informação. No contexto da contemporaneidade, em que as tecnologias digitais tornam ainda mais simbiótica essa relação há risco de sobrecarga cognitiva e, por isso, a necessidade de redução e adequação da carga informacional de modo relevante às audiências (Correia, 2009 p.187)

Um dos pensadores que atualmente mais investiga a complexidade da sociedade do século $X X I$, o filófoso sul-coreano Byung-Chul Han apresenta reflexões relevantes sobre as tecnologias da era digital e as relações de trabalho estruturadas pelo neoliberalismo. Segundo Han, a sociedade do desempenho de hoje é também a sociedade do esgotamento, do cansaço. Há nela um "excesso da elevação do desempenho" que conduz "a um infarto da alma." (Han, 2019, p.71).

Relacionando as ideias de Han, esmiuçadas a seguir, à área da educação em design através do diálogo com autores do campo e próximos a ele -, este estudo pretende levantar discussões sobre os possíveis reflexos que o colapso nos processos cognitivos e comunicativos, realizados pelos indivíduos da sociedade do século XXI, provoca nos estudantes de design. Se os sujeitos de desempenho de hoje, submetidos à exaustão, já não sabem mais o que produzem, nem o que consomem, é possível evitar que o mesmo fenômeno possa ser observado na prática cotidiana destes futuros designers?

\section{A sociedade do desempenho e seu excesso de positividade}

Ao pensar a sociedade do século XXI, Byung-Chul Han apresenta um contraponto à ideia de poder conceituada por Michel Foucault. Segundo Han, a sociedade de hoje deixa de ser disciplinar para tornar-se uma sociedade de desempenho. Seus habitantes, não mais "sujeitos da obediência", são agora sujeitos de desempenho e produção, o que os faz serem "empresários de si mesmos". (2019, p. 23).

Se a sociedade disciplinar de Foucault é a da negatividade de um poder que proíbe, reprime e constrange, a sociedade de desempenho de hoje desvincula-se, através da desregulamentação, desta negatividade.

O poder ilimitado é o verbo modal positivo da sociedade de desempenho. [...] No lugar de proibição, mandamento ou lei, entram projeto, iniciativa e motivação. A sociedade disciplinar ainda está dominada pelo não. Sua negatividade gera loucos e delinquentes. A sociedade do desempenho, ao contrário, produz depressivos e fracassados. (Han, 2019, pp. 24-25). 
De acordo com Han, o desejo de maximizar a produção, que já existe na sociedade disciplinar, tem continuidade na sociedade de desempenho. No entanto, a negatividade da proibição imposta àquele sujeito da obediência se choca com os limites da produtividade. Nesse sentido, a mudança de paradigma da disciplina para o desempenho - a adoção de um esquema positivo do poder - se dá também como forma de elevar a produtividade. Para o filósofo, "a negatividade da proibição tem um efeito de bloqueio, impedindo um crescimento maior. [...] O sujeito de desempenho é mais rápido e produtivo que o sujeito da obediência." (2019, p.25).

Han alerta para o consequente esgotamento que atinge o humano da atualidade. Deprimido pela pressão que sofre, o sujeito de desempenho tem, no excesso de positividade, sua alma consumida. Nas palavras do autor, a depressão

[...] irrompe no momento em que o sujeito de desempenho não pode mais poder. Ela é de princípio um cansaço de fazer e de poder. A lamúria do indivíduo depressivo de que nada é possivel só se torna possível numa sociedade que crê que nada é impossível. Não-mais-poder-poder leva a uma autoacusação destrutiva e a uma autoagressão, o sujeito do desempenho encontra-se em guerra consigo mesmo. (Han, 2019, p. 29).

Para Han, o sujeito de desempenho se distingue do sujeito de obediência pela ausência do domínio externo. O sujeito de desempenho não é explorado pelo outro, mas explora a si mesmo. O sentimento de liberdade que parece fazer parte da vida do sujeito de desempenho é, portanto, paradoxal; transforma-se em violência, "em virtude das estruturas coercitivas que Ihe são inerentes." (2019, p.30).

$\mathrm{Na}$ combinação entre uma enorme carga de trabalho e o bombardeamento de "estímulos, informações e impulsos" (Han, 2019, p.31), o sujeito se vê condicionado à multitarefa, o que seria, segundo o filósofo, não uma grande habilidade do ser humano pós-moderno, mas sim um retrocesso, técnica característica dos animais em estado selvagem em que são obrigados a um estado de permanente atenção para sobreviverem.

\section{A formação de sujeitos questionadores}

Desvinculado da sociedade disciplinar pela quebra de regras, o sujeito de desempenho parece libertar-se, enfim, de toda a repressão. No campo do design, a inauguração das discussões alavancadas pelo design gráfico pós-moderno no início da década de 1980, como afirma Poynor (2010, p.12) conduz ao desenvolvimento de produtos caracterizados pela fragmentação, superficialidade, pluralismo, entre outros aspectos que levam a "problematizar" os significados de modo aberto à interpretação.

Se "problematizar o significado" é também criar outros possíveis, é preciso, antes de mais nada, dominar o primeiro. No design, qualquer norma pode ser desobedecida, qualquer imagem - e sua mensagem - pode ser contestada desde que analisadas com precisão as suas configurações. Ao citar o designer e professor britânico John Lewis - que escrevera, ainda em 1963, um livro no qual um dos capítulos é "As regras foram feitas para serem quebradas" -, Poynor afirma que ele admitia a ilegibilidade, a mistura de fontes e a mutilação 
de letras, "desde que a serviço da mensagem e acrescentando algum tipo de entusiasmo." (2010, p.12)

Em Novos Fundamentos do Design, Lupton e Phillips (2008) enfatizam a preocupação em se estimular o equilíbrio entre as habilidades técnicas e o pensamento visual e crítico nos alunos de design da era digital. Como forma de combater a defasagem que acreditam existir entre o uso dos softwares e o pensamento visual, revisitam as estruturas formais tradicionais do design moderno - com forte menção à Bauhaus — através de trabalhos de estudantes de graduação e pós-graduação contemporâneos.

Na percepção das autoras, conceitos que sempre estiveram presentes nas artes gráficas, como a transparência e as camadas, são agora renovados graças à "acessibilidade irrestrita" que os programas trazem. "Designers gráficos modernos sempre trabalharam com a transparência, mas nunca tanto quanto hoje, quando esse recurso pode ser instantaneamente manipulado por meio de ferramentas fáceis de usar." Há que se perguntar, no entanto, o significado desses elementos visuais: "o que a transparência quer dizer?" (Lupton \& Phillips, 2008, p. 9).

Defensora de uma abordagem humanística do design de informação, Lupi (2017) também problematiza o frequente "retoque cosmético" pelo qual passam os dados na tentativa de tornálos mais compreensíveis. A popularização dos infográficos, segundo a designer, se deve à falsa alegação de que a combinação de alguns pictogramas com números em tamanho grande resolveria o problema de "simplificar a complexidade" dos fenômenos que governam nosso mundo. De fato, basta uma navegação rápida em aplicativos de compartilhamento de imagens como o Pinterest para encontrar, na categoria infographic design, uma gama enorme de templates muito semelhantes entre si: mesmos elementos, formas e cores.

Figura 1: Templates de infográficos disponibilizados no Pinterest

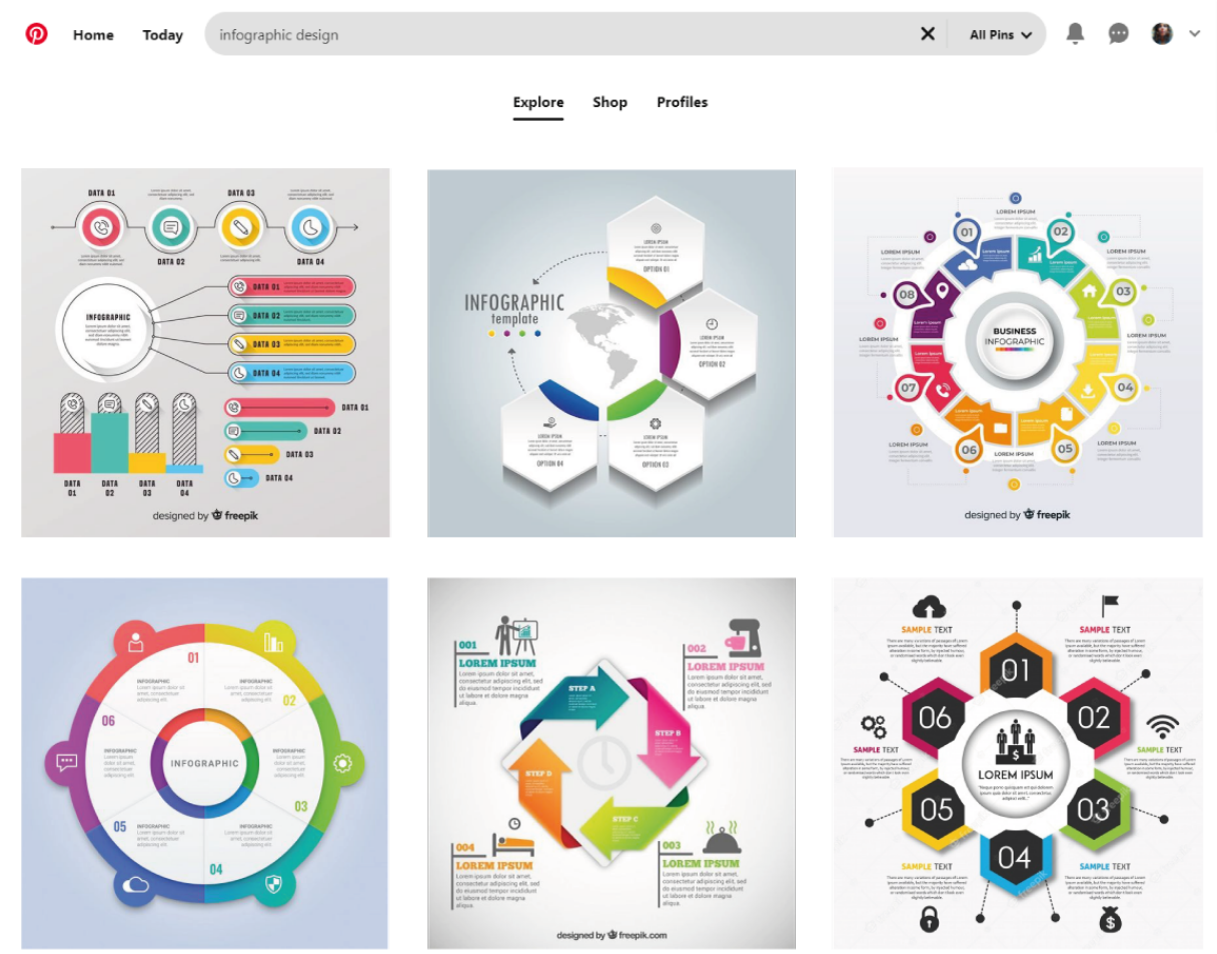


Prática comum entre os estudantes, essa busca fácil e imediata por referências no mundo digital por vezes funciona como receita de bolo. Reproduzo o que vejo, logo crio imagens de sucesso. Mas quais articulações, quais significados, quais mensagem estão por trás da construção delas?

Na sociedade do cansaço há que se combater o esgotamento também da criação de novas imagens, suas mensagens e significados. Com tal estoque de referências facilmente acessíveis em bancos digitais, há hoje uma espécie de pasteurização da comunicação visual, fazendo parecer que os designers, mundo afora, têm um mesmo repertório. Nesse sentido, o ensino de design da informação pode estimular a fusão de tecnologias, encorajando os estudantes a se aproximarem da materialidade das coisas físicas - texturas, cores, cheiros - , ainda que num segundo momento a transponham para o universo digital. Pode orientar a experimentação de novas técnicas manuais e ferramentas analógicas, permitindo "profundos níveis de pesquisa e pensamento - esta zona de destilação que ultrapassa o apetite mediano para testar novos terrenos e explorar alternativas." (Lupton \& Phillips, 2008, p. 9).

As visualizações de dados densos e não convencionais promovem a lentidão - uma meta particularmente pungente a ser definida em nossa era de períodos de atenção cada vez mais curtos. Se pudermos criar recursos visuais que incentivem a leitura cuidadosa e o envolvimento pessoal, as pessoas encontrarão cada vez mais valor real nos dados e no que eles representam. (Lupi, 2017).

Mas como propor aos estudantes uma abordagem experimental e outro tempo de aprendizagem, quando as informações acerca da profissão contribuem para uma expectativa da performance, alinhada ao domínio dos softwares? Fica claro que um dos desafios consiste em lidar com as expectativas de professores e estudantes, passando necessariamente pelo (auto)questionamento das relações de ensino-aprendizagem. Se por um lado é importante que os estudantes abram mão da urgência em dominar softwares e produzir trabalhos em ambientes digitais controlados, permitindo lançarem-se a possibilidades outras, por outro, é também fundamental que os professores abdiquem de seus dispositivos de controle e desempenho, focando menos em resultados e mais em processos. Sem liberdade e confiança dificilmente os estudantes se lançarão ao desconhecido.

\section{A Pedagogia do Ver, a habilidade artesanal e o tempo da reflexão}

O conceito da Pedagogia do Ver de Byung-Chul Han apoia-se nos pensamentos de Nietzsche para abordar a incapacidade humana de oferecer resistência a um estímulo. Aprender a ver é "habituar o olho ao descanso, à paciência", é capacitá-lo "a uma atenção profunda e contemplativa, a um olhar demorado e lento." (Han, 2019, p.51) Segundo Han, a revitalização da vita contemplativa que Nietzsche propõe é essa soberania sobre os muitos estímulos que atravessam, sobretudo, o ser humano contemporâneo.

Hoje, vivemos num mundo muito pobre de interrupções, pobre de entremeios e tempos intermediários. [...] A atividade que segue a estupidez da mecânica é pobre em interrupções. A máquina não pode 
fazer pausas. Apesar de todo o seu desempenho computacional, o computador é burro, na medida em que Ihe falta a capacidade para hesitar. (Han, 2019, p. 54).

Nesse sentido, em contraponto à pressa do ritmo maquínico - ao qual escapa esse tempo do hesitar e que é, ainda hoje, diretamente relacionado aos processos produtivos do design -, pode-se recorrer à ideia de "habilidade artesanal" de Sennet. Afirmando que a expressão nada tem a ver com um estilo de vida dizimado pela sociedade industrial, Sennet ressalta que a habilidade artesanal não diz respeito somente à habilidade manual, mas a qualquer atividade que, praticada com empenho, tende a ser melhor e mais capacitada, como um programa de computador, os cuidados paternos, a cidadania. A habilidade artesanal vincula-se a uma prática que tem como pergunta norteadora o como se fazer, mas também o porquê de se fazer; uma prática que concentra seus esforços no processo criativo da feitura das coisas, conectando-o aos problemas complexos do campo.

Assim, o bom artífice é, segundo Sennet, aquele que faz a prática dialogar com as ideias, mantendo uma relação íntima entre a mão e a cabeça. Dessa forma, "evolui para o estabelecimento de hábitos prolongados, que por sua vez criam um ritmo entre a solução de problemas e a deteç̧ão de problemas." (2009, p. 17) Os artífices se engajam em ações que são nada menos que laboratórios nos quais os sentimentos e as ideias podem ser investigados.

Trazendo a discussão para o contexto da educação, Schön denomina de "ensino prático reflexivo" o modelo de aprendizagem através do fazer. Baseando-se na pedagogia da ação de John Dewey em que o estudante precisa aprender por si próprio as relações entre os meios e métodos empregados e os resultados atingidos (DEWEY apud SCHÖN. 2000), Schön sugere os conceitos de "conhecimento na ação" e "reflexão na ação". O primeiro diz respeito ao conhecimento tácito; é espontâneo, está implícito no fazer. O segundo acontece quando este fazer revela algum elemento inesperado, nos levando a refletir como o conhecimento na ação gerou um resultado imprevisível. Nesta situação, podemos interromper a ação para pensar sobre ela, dissociando a reflexão da ação; ou pensar sobre ela enquanto acontece, sem interrompê-la, podendo naquele mesmo momento interferi-la. Para Schön,

Uma aula prática é um mundo virtual, relativamente livre de pressões, distrações e riscos do mundo ao qual, no entanto, ele diz respeito. Fica no espaço intermediário entre o mundo prático, a camada 'leiga' da vida ordinária e o mundo esotérico da academia. É também um mundo coletivo em si, com sua própria mistura de materiais, ferramentas, linguagens e apreciações. Incorpora maneiras particulares de ver, pensar e fazer que tendem, com o tempo, a ter sua autoridade cada vez mais reforçada na visão do estudante. (Schön, 2009, p. 40).

Desse modo, antes de se propor uma prática reflexiva, é preciso deixar claro aos estudantes que trata-se de outra abordagem pedagógica. A proposta do praticante reflexivo de Schön é, por princípio, desvinculada de uma abordagem meramente instrucional e que afere o desempenho dos estudantes mediante testes e provas. Cabe, portanto, repensar os próprios processos pedagógicos e avaliativos de modo a comportar as subjetividades, as experimentações e os imprevistos, o que implica em uma mudança radical de postura por parte dos professores. 


\section{Considerações finais}

Ao abordar os desempenhos culturais da humanidade, Byung-Chul Han discorre sobre a importância da contemplação, da necessidade de se ter ambientes nos quais seja possível uma atenção profunda. A atenção dispersa, característica dos sujeitos da sociedade de desempenho, promove uma "rápida mudança de foco entre diversas atividades, fontes informativas e processos." (2019, p.33).

Não elaborado para o tédio profundo, o sujeito de desempenho não experimenta nesse momento a chave para o processo criativo, que conduz a um movimento totalmente novo. $O$ sujeito que tolera o tédio, ao se entediar no andar, perceberá que pode se balançar ou dançar. "Comparada com o andar linear, reto, a dança, com seus movimentos revoluteantes, é um luxo que foge totalmente do princípio do desempenho". No tédio profundo, na contemplação, encontra-se "o espanto a respeito do ser-assim das coisas, afastado de toda e qualquer exequibilidade e processualidade." (2019, p.35).

A dúvida moderna cartesiana dissolve o espanto. A capacidade contemplativa não está necessariamente ligada ao ser imperecível. Justamente o oscilante, o inaparente ou o fugidio só se abrem a uma atenção profunda, contemplativa. Só o demorar-se contemplativo tem acesso também ao fôlego, ao lento. (...) Paul Cézanne, esse mestre da atenção profunda, contemplativa, observou certa vez que podia ver o perfume das coisas. (Han, 2019, p. 32).

Ver o cheiro das coisas, ver a textura das coisas requer tempo. O tédio profundo que conduz à criação do novo, como alega Han, requer tempo. E o tempo da tecnologia digital já não é o mesmo da analógica, nem da habilidade artesanal de que fala Sennet. A rapidez com que se criam, se copiam e colam elementos nos softwares, é a mesma com que se apaga, se volta atrás. O imprevisível, o acaso, o erro - aspectos da vida real - são extintos pelo computador. $\mathrm{Ctrl}+\mathrm{C}, \mathrm{C}$ trl+V, $\mathrm{C}$ trl+Z: estes comandos mecânicos que constroem imagens em frações de segundos, muitas vezes não são, por sua rapidez, acompanhados pelo pensamento visual - por ele, que deveria ser o grande comandante do processo criativo. Nem mesmo os dados são perfeitos, como afirma Lupi (2017), uma vez que são, principalmente, produzidos nós, humanos: sua visualização "deve abraçar a imperfeição e a aproximação".

Ao mesmo tempo, as pressões sofridas pelos professores por prazos e notas também podem levá-los a abordagens pedagógicas através das quais possam exercer maior controle, além de avaliarem os estudantes com mais facilidade e eficiência. O controle e a repetição são, entretanto, obstáculos para que se fomente a experimentação e a contemplação. Portanto, cabe também aos docentes uma mudança de mentalidade de modo a combater a perspectiva imposta pela sociedade do desempenho/cansaço.

Segundo Lupi (2017), "estamos prontos para questionar a impessoalidade de uma abordagem meramente técnica dos dados e começar a projetar maneiras de conectar os números ao que eles realmente representam: conhecimento, comportamentos, pessoas." Nesse sentido, um ensino de design da informação que incorpore em suas práticas pedagógicas a temporalidade do hesitar pode formar indivíduos mais atentos à construção de novos significados. Pode formar mais artífices e menos sujeitos de desempenho. 


\section{Agradecimento}

Nosso agradecimento à FAPERJ — Fundação Carlos Chagas Filho de Amparo à Pesquisa do Estado do Rio de Janeiro, pelo apoio ao desenvolvimento da tese (em andamento) a partir da qual se elaborou este artigo.

\section{Referências}

Correia, M. (2009). A comunicação de dados estatísticos por intermédio de infográficos: uma abordagem ergonômica. Dissertação (Mestrado em Design). Pontifícia Universidade Católica do Rio de Janeiro - PUC-Rio.

Han, B-C. (2019). Sociedade do cansaço. Petrópolis: Vozes.

Jacobson, R. (2000). Information design. Cambridge: The MIT Press.

Lipton, R. (2007). The pratical guide to information design. New Jersey: John Wiley \& Sons.

Lupi, Giorgia. (2017). Data humanism, the revolution will be visualized. http://giorgialupi.com/data-humanism-my-manifesto-for-a-new-data-wold/

Lupton, E., \& Phillips, J. C. (2008). Novos fundamentos do Design. São Paulo: Cosac Naify.

Poynor, R. (2010). Abaixo as regras: design gráfico e pós-modernismo. Porto Alegre: Bookman.

Schön, D. (2000) Educando o profissional reflexivo: um novo design para o ensino e a aprendizagem. Porto Alegre: Artmed.

Sennet, R. (2009). O Artífice. Rio de Janeiro: Record.

Wildbur, P., \& Burke, M. (1998). Infográfica. Soluciones innovadoras en el diseño contemporáneo. Barcelona: Gustavo Gili.

\section{Sobre o(a/s) autor(a/es)}

Ana Dias de Alencar, Doutoranda., ESDI/UERJ, Brasil adias@esdi.uerj.br Ricardo Artur Pereira Carvalho, Dr., ESDI/UERJ, Brasil rartur@esdi.uerj.br 